\title{
Lineage commitment in the mammalian preimplantation embryo
}

\author{
Peter L. Pfeffer \\ 70 Nevada Road, 3216 Hamilton, New Zealand
}

\begin{abstract}
Summary
Early embryo mortality during the first two weeks of development is an important factor in the decreasing fertility of dairy cattle. During this period the embryo needs to correctly establish the first three lineages, namely epiblast, hypoblast and trophoblast so as to survive. The morphological and molecular events underlying these lineage decisions are discussed, drawing on information derived predominantly from mice and cattle.
\end{abstract}

\section{Introduction}

In cattle, gestation lasts around 280 days (average range 273-291 days) with the first six weeks constituting the embryonic period (Winters et al. 1942). In this period the body plan is established and most of the organ systems are formed (Fig. 1), while the subsequent foetal period is characterised by growth and modelling. The embryonic period has been divided into two time windows of three weeks, appropriately termed "early" and "late", with the beginning of implantation straddling this transition. Thus starting at Day 19, in what is termed the apposition phase of implantation, cell to cell contact is established between the trophoblast of the conceptus and the uterine epithelium (Guillomot 1995). While the term "attachment" has been suggested to supplant that of "implantation" because of the minimal invasiveness of the ruminant placenta, we shall use the latter term based on its more generic applicability.

There has been a resurgence of interest in cattle gestation owing to declining conception rates in dairy cattle (Diskin \& Morris 2008) and the high financial costs associated with this. For example, Australian reproductive management programmes estimated (in 2007) that a $1 \%$ increase in the 6 -week in calf would be worth $\$ 400$ per 100 cows in the herd while a $1 \%$ reduction in empty rate amounted to $\$ 570$ per 100 animals (Burke et al. 2008).

The events affecting conception rate can be separated into four categories. These are, in chronological order, (i) fertilisation, (ii) early embryonic, (iii) late embryonic and (iv), foetal development. Fertilisation failure is estimated to lie between 5 and 17\% (Sartori et al. 2010, Walsh et al. 2011). Early embryonic losses (Fig. 1), encompassing the first three weeks of postfertilisation development range from $28 \%$ (beef and dairy cows 1980 genetics) to $40 \%$ (N.American genetics high producing dairy cows) (Diskin \& Morris 2008, Diskin et al. 2011). Late embryo losses occurring between Days 22 and 42 contribute an estimated 5-10\% to conception failures whereas foetal deaths during the remainder of gestation are also relatively 


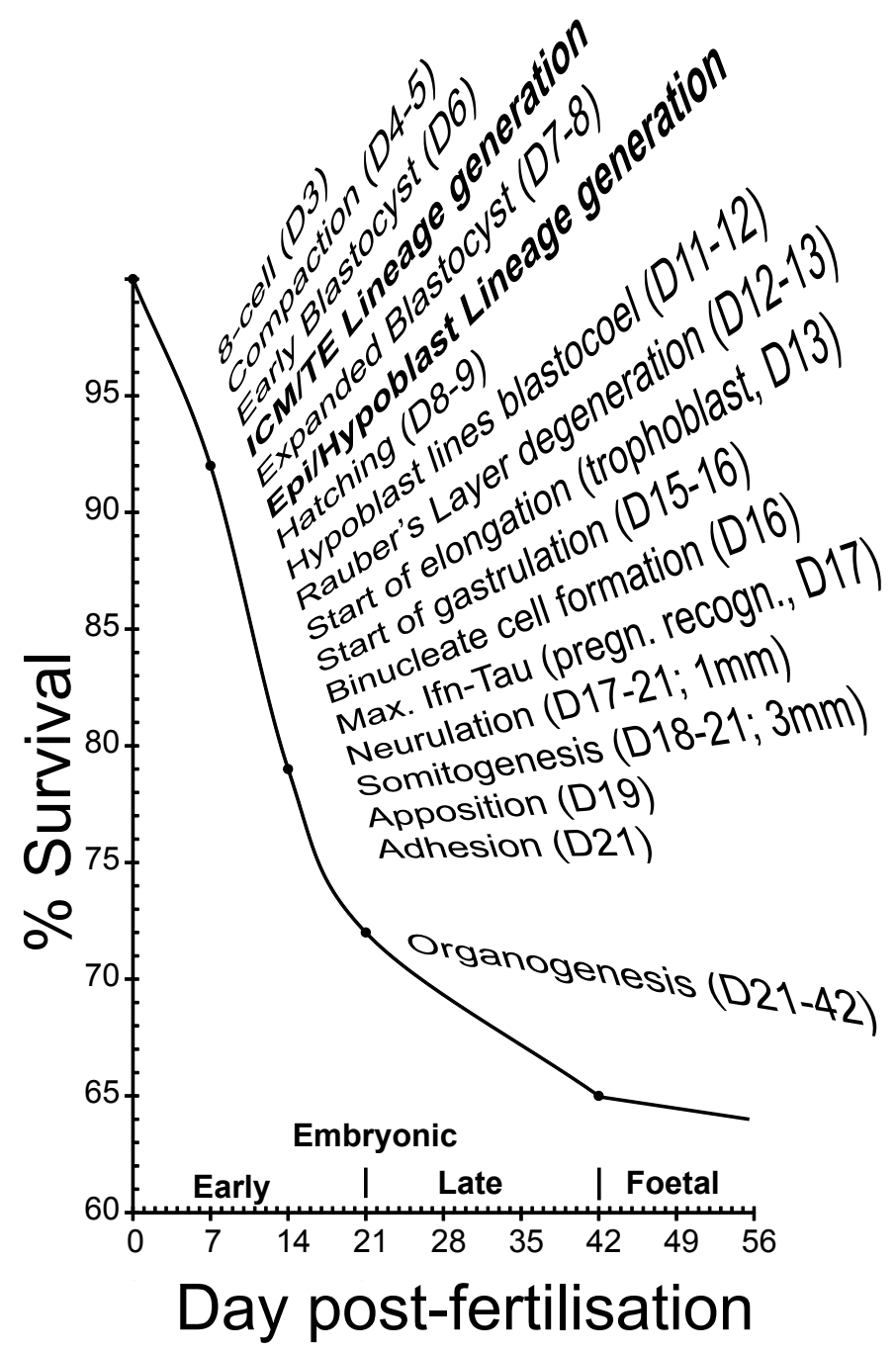

Figure 1. Developmental events in cattle in relation to embryo mortality rates. Days subsequent to fertilisation are plotted against the typical percentage of fertilised embryos surviving (references in main text). The greatest drop in survival is seen during the early embryonic period (developmental periods are shown along the x-axis). The critical nature of this period is highlighted by the number of key developmental events occurring in this phase, as listed along the survival curve in the graph. Events discussed in detail in this review are shown in bold.

low (6\%) (McDougall et al. 2005, Diskin et al. 2011). The major part of early embryo loss in cattle occurs in the first two weeks after breeding (Boyd et al. 1969, Ayalon 1978, Diskin \& Sreenan 1980, Roche et al. 1981, Dunne et al. 2000, Berg et al. 2010), with some evidence suggesting that high losses are already evident by Day 8 (Maurer \& Chenault 1983, Wiebold 1988, Sartori et al. 2010).

This high mortality during early embryo development underscores the functional importance of the preimplantation phase of development and in particular the first two weeks during which the major embryological events concern the establishment of the first three lineages (Fig 1). 
From an evolutionary aspect, it is advantageous for the species to impose the greatest selection pressure for embryo viability at early gestational stages as it minimises the reproductive cost for the mother. From a developmental view, errors occurring during early developmental tend to have more dire consequences due to the progressive nature of development. This review will focus on the first two lineage determining events occurring during cattle early embryogenesis, presenting this in comparison to knowledge derived from other mammals.

\section{Creating asymmetry}

The earliest stages of eutherian mammalian development are characterised by the absence of asymmetry and up to the morula stage, cells appear to be homogeneous in terms of morphology and molecular characteristics. This cell to cell equivalency has been borne out in functional experiments showing that all cells of the 2- to 8-cell stage embryo are totipotent. For example, in cattle as well as mice, separated individual cells (blastomeres) of the 4-cell embryo can develop into adulthood (Tarkowski \& Wroblewska 1967, Johnson et al. 1995). In sheep this has been shown even for individual cells of the 8-cell embryo (Willadsen 1981). How then is asymmetry or difference, necessary for establishing different lineages, introduced? And once introduced, how are these differences fixed or, in other words, how do the cells of different lineages become committed to their eventual fate?

In the mouse cell polarity, as well as inside/outside location within the cleavage stage embryo has been linked to cell lineage determination. In this species all blastomeres of the 8-cell stage embryo develop radial polarity concomitantly with compaction, the process by which blastomeres huddle together mediated by apical depletion of Cadherin-1 (E-cadherin; Ovumorulin) (Johnson \& Ziomek 1981, Peyrieras et al. 1983). During subsequent mitosis, dependant on the division plane, daughter cells will either remain polar and located at the outside of the compacted 16-cell morula or, after tangential divisions, half will become apolar and situated on the inside. Lineage tracing has shown inside apolar cells to contribute predominantly to the inner cell mass (ICM) (Pedersen et al. 1986). Conversely, after a further round of division the remaining polarised outside cells of the 32-cell embryo are fated to form trophoblast (Pedersen et al. 1986).

Initially it was suggested that the relative position (inside versus outside) and thus environment of a cell was the symmetry-breaking event generating the two lineages (Tarkowski \& Wroblewska 1967). Later on, the polarity model was proposed, emphasising cell polarisation with subsequent unequal partitioning of apical domain components as deterministic for differential lineage generation (Johnson \& Ziomek 1981). Both models are experimentally supported (Nishioka et al. 2009, Stephenson et al. 2010) and are indeed non-exclusive. More recent advances in imaging technologies and sensitivities have however uncovered unexpected heterogeneity and fluctation in the distributions of lineage-associated transcription factors such as Cdx2, Nanog and Gata6 (Dietrich \& Hiiragi 2007, Ralston \& Rossant 2008, Plachta et al. 2011), as well as extensive cell rearrangements during cleavage stages (Kurotaki et al. 2007, Dard et al. 2009). This opens up the possibility that symmetry breaking is a stochastically initiated selforganising system dependent on not a single factor (such as either polarity or cell position), but on multiple factors including cell characteristics such as polarity and gene expression as well as cell-cell interactions that may be either mechanical or biochemical (Wennekamp et al. 2013). This model posits i) that individual factors contribute in a quantitative manner to cell fate in a manner dependent on a cell's specific temporal and spatial context and ii) that factors are interconnected, leading to positive and negative feedback loops. 
Such a framework is more suited to explaining differential timings of early events among mammals. In cattle, using scanning electron microscopy, differences in microvilli distribution in individual blastomeres were seen in nearly all 16-cell cattle embryos with approximately $40 \%$ polar cells per embryo. No embryos contained more than $57 \%$ polar cells (Koyama et al. 1994). The polar sides were not always aligned to the outside indicating that the blastomere could rotate and so their position was not yet fixed. Indeed, compaction and the first appearance of apolar distributions of Cadherin-1 and Beta-catenin specifically in outer cells was only seen at the 32-cell stage (Betteridge \& Flechon 1988, Van Soom et al. 1997, Barcroft et al. 1998), two cell divisions later than in the mouse. Yet cattle embryos can already contain inner cells from the 16-cell stage onward with compaction and inner cell allocation being largely independent from each other (Van Soom et al. 1997). Thus the potential causative agents of symmetry breaking, namely cell position and polarity, occur in the opposite temporal sequence to the mouse. Cattle embryos would therefore be an interesting alternate system to test predictions of the various symmetry breaking models. To date however no such lineage studies have been performed.

\section{Fixation of the first lineages}

Shortly after compaction, a cavity, named the blastocoel develops. As the blastocoel expands, the inner cells are pushed to one side of the embryo and are now termed the inner cell mass, or ICM. These cells are morphologically quite distinct from the outer layer of polarised epithelial cells which is termed the trophectoderm (TE). In mice the TE has been shown to give rise to all the trophoblast, namely the conceptus-derived part of the placenta, whereas the ICM cells make up the rest of the conceptus, that is the embryo proper (foetus) and the various extraembryonic membranes such as the yolk sac, amnion and allantois (Copp 1979, Dyce et al. 1987). Thus by the blastocyst stage the first major split in lineages has taken place. However, it is only recently was the fate of cattle TE cells has been followed. TE cells from Day 7 expanded blastocysts were labelled with the lipophilic lineage tracer Dil, then replaced into recipient cows to be flushed out a week later. At this pre-gastrulation stage embryos had started elongating and the ICM had differentiated into the epiblast and extraembryonic hypoblast. No contribution of label to the latter two lineages was detected, confirming the mouse results that the TE, once specified, maintains its trophoblast character in a minimally manipulated embryo (Berg et al. 2011).

Equally important though is the question as to when the fate of a cell is irreversible, or in embryological terms, when is a cell committed to its expected fate. This can be measured by various means, but the principle is to place a cell in a novel cellular context and determine whether it retains its original fate (and thus is committed) or assumes the fate of its new neighbours (not committed). In mice various types of aggregation experiments revealed that up to the 32-cell stage outer prospective TE cells were not committed to the trophoblast fate (Rossant \& Vijh 1980, Tarkowski et al. 2010). However once embryos had started to cavitate (post 32-cell stage; early blastocysts), commitment of outer cells to their respective fates had occurred (Suwinska et al. 2008). Inner blastomeres of mice appear to be somewhat more plastic and, depending on the experimental set-up, seem to commit to an ICM fate somewhere between mid and late blastocyst stages (Rossant \& Lis 1979, Suwinska et al. 2008, Szczepanska et al. 2011, Grabarek et al. 2012).

In cattle, ICM cells isolated at Day 7 or 9 post-ovulation by immunosurgery were aggregated to Day 4.5, 16-cell embryos. Chimerism was detected at Day 13 and in born calves with the aid of chromosome markers (Picard et al. 1990). The pre-hatching stage ICM cells (Day 7) yielded chimeras, whereas when using post hatching donor cells, only one "inconclusive" Day 13 
chimera was obtained. As contribution to the trophoblast was not examined, no conclusion can be drawn as to commitment. However these experiments indicated that aggregation experiments with cells of at least 3 days difference in development were feasible, setting the stage for testing the commitment of cattle TE cells. For this experiment, Dil labelled enzymatically separated TE cells from expanded Day 7 blastocysts were sandwiched between totipotent blastomeres of 8-cell (Day 3) embryos (Fig. 2) and allowed to develop for 4 days in culture to the expanded blastocyst stage (Berg et al. 2011). It was found that one third of the transposed TE cells contributed to the ICM. That the Day 7 TE-derived cells that were located in the ICM were truly fated to ICM derivatives was proven by repeating the experiment with LacZ-transgenic host embryos and transferring the chimeras to recipient cows. When embryos were retrieved at early gastrulation stages, it was found that the blastocyst TE-derived cells had contributed extensively to inner cell mass derived hypoblast (Berg et al. 2011). In contrast, when TE cells from pregastrulation (Day 14) embryos were used for the sandwich chimeras, contribution was nearly exclusively to the TE, indicating that commitment of TE cells to trophoblast occurred between the expanded blastocyst stage and gastrulation, distinctly later than in mice.

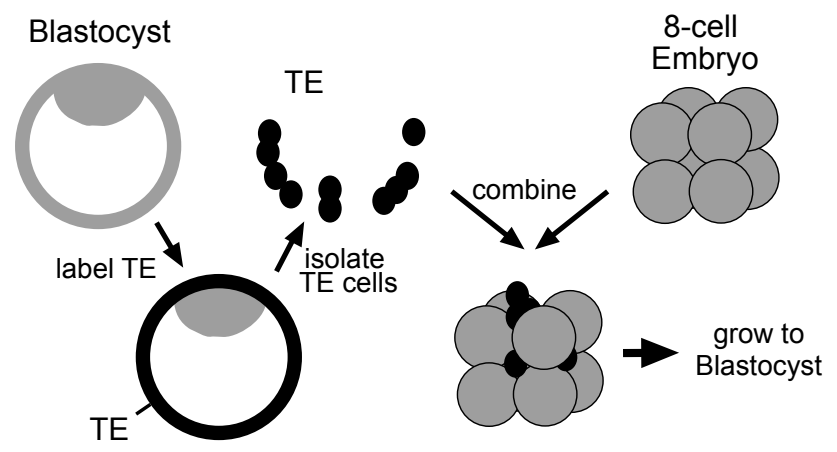

Figure 2. Experimental approach for determining the commitment of cattle trophectoderm cells. Expanded donor blastocysts are labelled with the lipophilic dye Dil (indicated in black) and TE cells are then isolated by microsurgically cutting the blastocyst followed by enzymatic dissociation. Concurrently zona-free host 8-cell embryos are grown in vitro (on right, grey) to provide an ectopic, uncommitted environment for the TE donor cells. After combining the donor and host cells, the chimeric embryos are allowed to develop to the expanded blastocyst stage and the contribution of the donor TE cells to ICM and TE can be traced using the fluorescent Dil label. If TE donor cells maintain their original fate and contribute only to $\mathrm{TE}$, they would be considered to have been committed to this fate at the stage that they had been isolated. If they were to contribute to both ICM and TE, they would be considered to have been uncommitted.

Recently, TE lineage commitment has also been addressed in humans. It was found that TE cells from full (late) Day 5 blastocysts were, upon reaggregation, able to form both ICM and TE, whereas TE cells from expanded Day 5 blastocysts were not (De Paepe et al. 2013). Furthermore, when full blastocyst-derived TE cells were placed on the inside of Day 5 blastomere aggregates, they could express NANOG, an ICM marker, a day later. Thus human TE cells are committed at a later blastocyst stage than mice, but earlier than cattle.

It is tempting to speculate that the timing of trophoblast commitment (normalised to the morphological stage of development) is determined by the timing of implantation. Mouse blastocysts implant a day, humans two to three days and cattle 12 to 13 days after blastocyst formation. Implantation requires trophoblast proliferation as well as differentiation so as to establish the necessary contact and interaction with the maternal epithelium. Hence the shorter 
the interval between TE specification and implantation, the sooner TE commitment has to take place.

\section{Molecular determinants of lineage specification in mice}

Much effort has gone into the elucidation of the critical lineage determining factors and their reciprocal interactions with symmetry breaking events, such as differential cell-cell signalling (inside versus outside cells) and distributions of cellular components (via polarity generating events). As the state of a cell as well as the reversibility or lability of that state is dependent on the gene regulatory network prevailing in that cell and its susceptibility to spatially and temporally changing signals, it is clear that transcription factors and signalling pathways play a paramount role in lineage fixation.

It is likely that the early gene expression program runs according to a developmental clock as mouse embryos halved at the 2-cell stage maintain the same timing of polarization, compaction, generation of inside cells, cavitation and cell fate allocation as whole embryo controls (Morris et al. 2012). In mice, single cell RNA-seq revealed enormous changes between matured oocytes and blastomeres of the 2-cell stage with 8000 down-regulated and 2000 up-regulated genes. This probably reflects maternal RNA degradation and embryonic genome activation. During the following 2 cell divisions, a further 5400 and 3400 genes were upregulated (Tang et al. 2011). Yet blastomere transcriptomes from individual 2-cell embryos were highly similar to each other (Tang et al. 2011). From the 8-cell (compaction) stage, mRNA (Guo et al. 2010) and nuclear protein (Dietrich \& Hiiragi 2007, Plusa et al. 2008) of lineage specific markers such as Oct4/Pou5f1 (ICM), Nanog (ICM/epiblast), Gata6 (ICM/hypoblast) and Cdx2 (TE) could be detected. Importantly, these factors remain coexpressed, though sometimes at varying levels until at least the 16-cell stage but begin to resolve by the early (32-cell, ca E3.25) blastocyst stage. Measuring RNA expression of 48 genes in individual cells of mouse preimplantation embryos also revealed a progressive refinement of differential gene expression. From the 32cell (nascent blastocyst) stage, inner (prospective ICM) and outer (TE) cells exhibited distinct expression profiles, while from the 64 cell stage cells epiblast and hypoblast signatures were apparent (Guo et al. 2010). Interestingly, the positional allocation of a cell (inside/outside) preceded the generation of differential (ICM/TE) gene regulatory networks. That cell-cell contact, and thus positional information, is important to establishing a state-specific gene network, was demonstrated directly by keeping blastomeres segregated from the 2-cell stage to the 32-cell stage. Such isolated individual 32-cell blastomeres resembled the normal 32-cell gene expression pattern, but assumed intermediate levels of lineage-specific genes, with overall a more TE-like gene expression profile (Lorthongpanich et al. 2012). Thus the gene expression programs are set into motion independently of symmetry-breaking events but have to be refined via cell-extrinsic signals.

A good candidate for driving the first resolution of TE and ICM gene expression programs is the Hippo signalling pathway which is believed to use cell polarity and position to modulate the TE-specific gene regulatory network as follows. In nonpolar cells such as the inner cells of the postcompaction morula, the Angiomotin proteins (Amot/Amot-like2) interact through Nf2A with Cadherin- 1 at adherens junctions. Cell-cell contact, presumably via Cadherin- 1 crosslinking causes the phosphorylation and stabilisation of Amot by the hippo pathway kinase Lats2. The resultant adherens junction-linked complex leads to the Lats2 mediated phosphorylation of Yesassociated protein (Yap) which prevents it from shuttling into the nucleus to activate its partner protein Tead4 (Nishioka et al. 2009, Cockburn et al. 2013, Hirate et al. 2013). Importantly Tead4 
is crucial for trophoblast development and the establishment of the TE-specific transcriptional program including expression of $C d x 2$, Eomes and Fgfr2 (Nishioka et al. 2008). Thus in inner cells cell contact leads to the repression of the TE-gene regulatory network, allowing the coexpressed ICM/pluripotency network to gain the upper hand.

However as all these factors are also expressed in outer cells which also display Cadherin-1 mediated cell-cell interactions along their mediobasal surfaces, why is Yap not retained in the cytoplasm as well? From the 8-cell stage onwards, outer cells are polarised containing an apical domain and a basolateral domain, separated by tight junctions. This is mediated by the polarity regulator complex aPKC-Par6-Par3. Disruption of the polarity complex destroys polarity increases cytoplasmic Yap in outer cells and shuts down the Tead4 directed TE gene regulatory network (Plusa et al. 2005, Alarcon 2010, Hirate et al. 2013). Interestingly from the 8-cell stage onward Amot is found only in the apical domain in polarised outer cells, whereas in inner apolar cells it is dispersed across the plasma membrane. This sequestering of Amot away from basolateral adherens junctions abrogates Hippo signalling resulting in nuclear Yap and Tead4 dependent TE transcription in outer cells (Hirate et al. 2013). Thus both cell polarity (via Tead4 activation) and subsequent inside-outside location (cell-cell contact in the respective absence-presence of polarity) are required to direct the differential gene expression programs.

Tead4 is ubiquitously expressed from the 2 cell stage (Yagi et al. 2007). Once activated via nuclear Yap, it accentuates expression of $C d x 2$ and, independently of $C d x 2$ expression, Gata3 and Eomes (Nishioka et al. 2009, Ralston et al. 2010). Cdx2 is one of the most central players in mouse TE lineage commitment and maintenance, as shown by a variety of in vivo and in vitro assays (reviewed in (Pfeffer \& Pearton 2012)) and its importance for TE maintenance has also been demonstrated in cattle, using a knock down approach (Berg et al. 2011). Aside from the establishment of the TE-specific gene regulatory network, $\mathrm{Cdx} 2$ is necessary to turn off the ICM-specific pluripotency network in outer cells by inhibiting Oct4 and Nanog (Niwa et al. 2005, Chen et al. 2009). These genes, as well as Sox2, stabilise each other's expression in ICM-derived embryonic stem cells, while repressing other lineages including that of the trophectoderm (Boyer et al. 2005). In the absence of Cdx2 expression, Oct4 is expressed at high levels in outer cells with concomitant loss of TE characteristics (Niwa et al. 2005, Strumpf et al. 2005). Cdx2 downregulates Oct4 expression via the conserved region 4 (CR4) of the distal Oct4 enhancer (Niwa et al. 2005, Wang et al. 2010). Importantly, Cdx2 can also inactivate Oct4 at the post-transcriptional level (Niwa et al. 2005, Nishiyama et al. 2009). Thus TE commitment may occur before Oct4 transcription is fully shut down as long as Cdx2 protein levels are in functional excess of Oct4 protein levels.

The protein-protein interaction between Cdx2 and Oct4 is mutually inhibitive (Niwa et al. 2005). In inner cells therefore, where Cdx2 is not maintained via Yap/Tead4, remaining Cdx2 activity is repressed by Oct 4 and the $\mathrm{Cdx} 2$-dependent TE-gene regulatory network is rapidly shut down with $\mathrm{Cdx} 2$ protein restricted to outer cells by the 32-cell early blastocyst (Dietrich \& Hiiragi 2007, Ralston \& Rossant 2008). The outer cell restriction of Cdx2 may also be accentuated by a recently discovered motif within the $3^{\prime}$ coding part of the $\mathrm{Cdx} 2$ transcript. This motif directs Cdx2 RNA to the apical region of polarised cells such that upon asymmetrical divisions outer cells inherit larger amounts of transcript (Skamagki et al. 2013).

\section{Molecular determinants of lineage specification in cattle}

In non-rodent mammals for which data are available, namely humans, monkeys, rabbits, pigs and cattle (van Eijk et al. 1999, Cauffman et al. 2005, Kuijk et al. 2008, Kobolak et al. 2009, 
Sritanaudomchai et al. 2009, Khan et al. 2012), Oct4 protein is seen in outer TE cells at later developmental stages than in mice. Expressing a GFP reporter under the control of either mouse or cattle Oct4 regulatory sequences in embryos of both mammals, inherent differences of Oct4 regulation in TE were shown (Fig. 3) (Berg et al. 2011). Cattle expanded blastocysts were unable to shut down in the TE a GFP-expressing mouse Oct4 reporter. At that developmental stage (expanded blastocyst) cattle Oct4 mRNA levels were shown to exceed those of $C d x 2$ ten-fold, suggesting that $\mathrm{Cdx} 2$ was unable to counteract Oct4 autoregulation. This was indeed shown by the lack of Oct4 upregulation upon $C d x 2$ knock-down. Thus high endogenous cattle Oct 4 activity was mediating via a known autoregulatory element the transcription of the introduced mouse Oct4 reporter in the TE (Berg et al. 2011). By inference it would indicate that the TE-gene regulatory network had not achieved prominence, which correlated well with the observed lack of commitment of cattle TE derived from such expanded blastocysts.

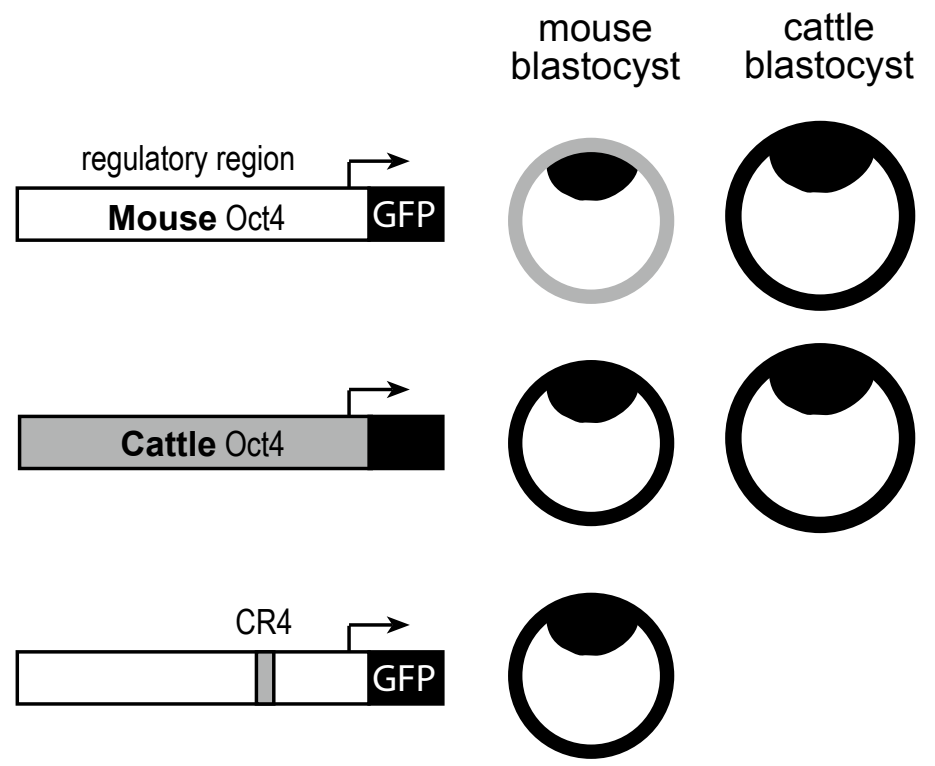

Figure 3. Differential trophectoderm regulation of Oct4 reporters in transgenic cattle and mouse blastocysts. A. A GFP reporter construct linked to $18 \mathrm{kbp}$ of mouse Oct4 regulatory sequences results in fluorescence (shown in black) restricted to the ICM of transgenic mouse but not cattle blastocysts. B. The equivalent cattle Oct4 regulatory construct continues to be expressed in the TE and ICM in both cattle and mouse embryos. $\mathbf{C}$. The difference in mouse and cattle Oct4 regulation is shown to lie within the CR4 region.

Secondly, it was found that the Oct4 regulatory regions of these species had diverged (Fig. 3). This was demonstrated in a reciprocal approach, that is, placing a cattle Oct4 reporter construct into mouse embryos. Expression of the cattle Oct4-reporter could not be extinguished in the mouse TE, even though these cells contained the necessary factors to switch off the endogenous mouse Oct4 gene. Noting sequence divergence in the distal Oct4 enhancer CR4, the authors replaced the mouse $C R 4$ region with that of cattle. Changing these $400 \mathrm{bp}$ in the context of the 18 kilobase mouse Oct4 reporter resulted in continued reporter expression in the mouse TE, in a cattle-like fashion. The regulatory difference was pinpointed to the exclusive presence in mice (as opposed to cattle, primates, rabbits and pigs) of two binding sites for the Tcfap2 family of transcription factors. The functional significance of these sites was supported by the ability, in vitro, of Tcfap2 proteins to inhibit transcription from an Oct4-CR4 luciferase construct (Berg 
et al. 2011). A recent report has questioned this based on the absence of Oct4 downregulation upon Tcfap2 knockdown (Choi et al. 2013). However this conclusion is questionable as only a modest knockdown of $60 \%$ was achieved and yet protein levels of Oct4, while restricted to the ICM in control embryos, failed to be extinguished in the TE of the Tcfap2c knockdown embryos shown (Choi et al. 2013), thus actually supporting a requirement for Tcfap2c in the TE-specific shut-down of Oct4. In summary, cattle and mouse embryos follow different trajectories in terms of lineage commitment based on differential $\mathrm{Cdx} 2$ levels and a change in the regulation of the ICM lineage specifier Oct4, as illustrated conceptually in Figure 4.

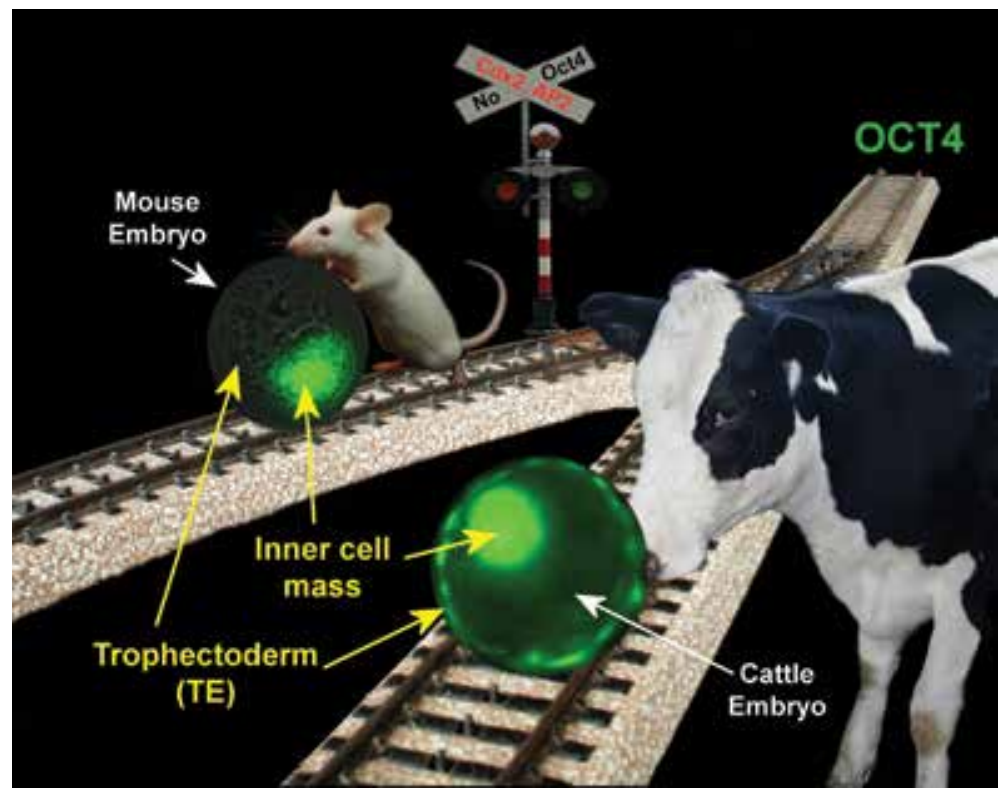

Figure 4. Conceptual visualisation of trophoblast commitment in cattle and mice. Cattle embryos stay on their developmental track with Oct4 expression ubiquitously activated and maintained in both the ICM and TE. In contrast, mouse embryos switch track via signals mediated through CDX2 and AP2 proteins, leading to Oct4 restriction to the ICM and an early commitment of TE tissue.

At later developmental stages, cattle Oct4 expression in the TE diminishes while Cdx2 levels remain constant. By E9 when the ICM has differentiated into epiblast and hypoblast layers, Cdx2 and Oct4 RNA levels are similar in the TE and by E11 Cdx2 is in 10 fold excess (Berg et al. 2011). The relatively delayed downregulation of cattle Oct4 in TE prompted the question as to whether this was causal for the corresponding delay of cattle TE commitment. To address this the $18 \mathrm{~kb}$ of cattle Oct 4 regulatory region was used to drive expression of a bicistronic Oct4IRES-GFP construct in a cattle-like fashion in mouse embryos (Fig. 5). Transgenic pronuclear injected embryos could be recovered at a frequency of $27 \%(12 / 45)$ at E4.5 to E6.5 with expression levels varying between weak and strong. Notably though, embryos with stronger expression exhibited a mosaic expression pattern at postimplantation stages and we were only able to generate 2 founders ( $5 \%$ ) from 42 pups born after pronuclear injection, with both lines showing exceedingly weak fluorescence at blastocyst stages. This suggests, but does not prove, that extended uniformly high Oct4 expression in the mouse TE is deleterious to mouse development.

The continued expression of Oct4 in cattle TE as well as the lack of commitment of this tissues at expanded blastocyst stages predicts that the TE-specific gene regulatory network has 

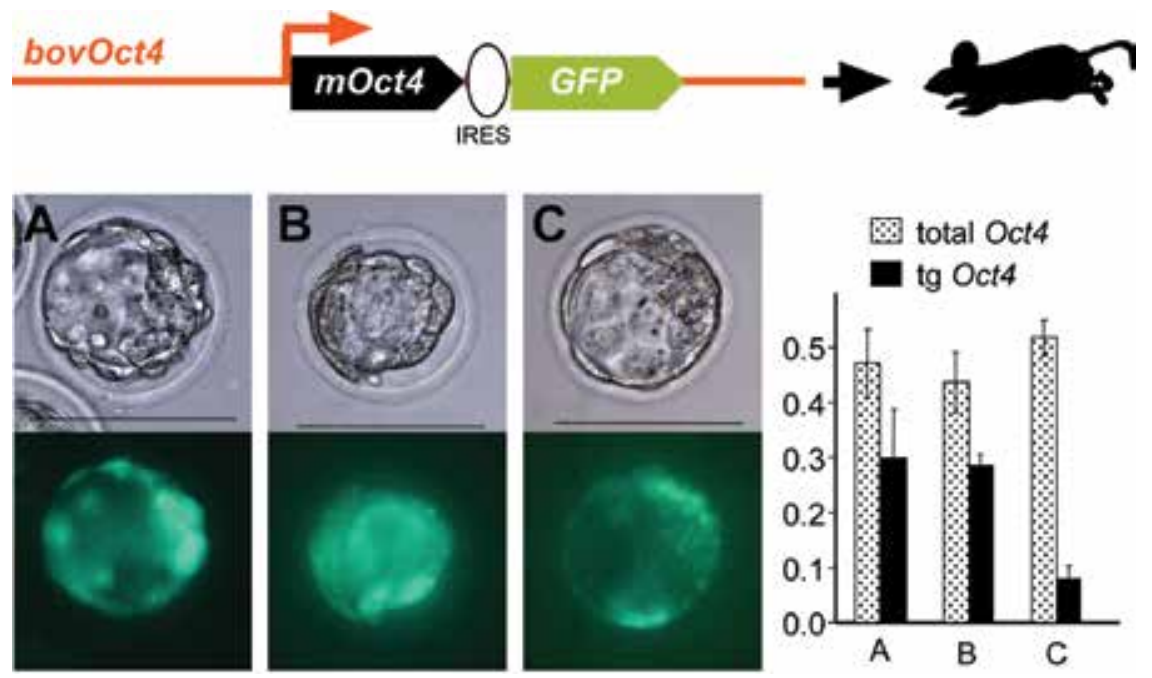

Figure 5. Expressing Oct4 in a cattle-like fashion in mice. An $18 \mathrm{kbp}$ cattle Oct4 regulatory region equivalent to that used by Berg et al., 2011, was modified, using recombineering technology, so as to splice in the mouse Oct 4 codons followed by an internal ribosome entry site (IRES) followed by GFP codons, thus allowing bicistronic expression of both mouse Oct4 and GFP in a cattle Oct4-like fashion. This construct was injected into the pronuclei of mouse zygotes to create transgenic embryos which were retrieved from recipients at E4 (late blastocyst stage). Panels A-C represent bright field and fluorescent images of three embryos which were subsequently analysed by quantitative real-time PCR for mRNA expression of the introduced and introduced + endogenous mouse Oct4 and normalised to three housekeeper genes. Non-restricted expression as expected from using the cattle Oct4 regulatory region was seen at these expanded blastocyst stages. Overall Oct4 levels were elevated relative to endogenous Oct4 expression, particularly in embryo C. The resultant phenotype of such transgenic embryos is discussed in the main text.

not been fully established. A global transcriptome comparison between Day 8 ICM and TE cells revealed 870 differentially expressed genes. However when comparing this data against a set of 120 curated mouse and human ICM/ES specific genes, only eight were found to be upregulated in cattle ICM while 6 were actually upregulated in the TE. The curated TE-specific dataset fared better with 12 of 49 genes upregulated in cattle TE and only 1 exhibiting a reciprocal expression pattern (Ozawa et al. 2012). While some mouse lineage commitment genes such as Nanog, Sox2 and Gata3 were higher in the equivalent bovine cell compartment, others such as Oct4 and Sall4 were not (Ozawa et al. 2012). Along similar lines, a second such study noted novel genes with ICM and TE restriction (Nagatomo et al. 2013). Two non-exclusive interpretations are possible. First, that similar to the Oct4 gene, the regulatory wiring has diverged among mammals. In support of this, a transcriptomic comparison of whole zygote to blastocyst stages among cattle, mice and humans led to an estimation that $40 \%$ of orthologous genes are differently expressed (Xie et al. 2010). Secondly, that the timing of the TE/ICM gene regulatory network establishment differs: Analysis of individual blastomere transcriptomes from 1-cell to morula stages in humans identified 9 developmental-stage specific modules of co-expressed genes of which 7 are preserved in mice, with the timing of these modules differing, mirroring the difference in EGA timing (Xue et al. 2013). 


\section{The second lineage decision}

The second lineage decision during mammalian embryogenesis involves the ICM lineage and follows close on the heels of the TE/ICM lineage split. This is the decision as to whether cells form the epiblast which will form the foetus and some extraembryonic mesoderm, and the hypoblast, which is the progenitor of the yolk sac but also contributes some endodermal cells. As the process has been well examined in mice, I will detail this model system first, using "hypoblast" as opposed to the equivalent term "primitive endoderm" throughout this discussion.

In mice, following compaction at the 8-cell stage, apolar cells located on the inside of the morula/blastocyst, are generated via asymmetric (radial) cleavage during two successive waves (8-16 and 16-32) of cell divisions. These inner cells coexpress both epiblast (Nanog) and hypoblast (Gata6) lineage markers, while the TE expression network is progressively shut down. By the midblastocyst 64-cell stage, a "salt and pepper" intermingling of Nanog and Gata6 positive cells in the ICM was observed. These cells were fated, but not fully committed, to epiblast or hypoblast as predicted by respectively Nanog or Gata6 expression (Chazaud et al. 2006). As reports sometimes differ as to exact timings, it should be pointed out that a mouse-strain dependency of when mutual exclusions occur, has been demonstrated (Frankenberg et al. 2011). Over the next few hours the mutually exclusive Nanog and Gata6 positive cells segregate such that the Gata6 hypoblast progenitors line the ICM/blastocyst cavity, whereas the "inner" ICM cells are Nanog positive (Chazaud et al., 2006; Plusa et al., 2008; Meilhac et al., 2009; Frankenberg et al., 2011). The end of sorting correlates with epiblast/hypoblast commitment (Grabarek et al. 2012). Implantation occurs by E4.5 ( $>100$ cells). Over this period a progressive series of hypoblast markers is switched on, starting with Gata6 at the 8-cell stage, followed by Pdgf (onset 16-32 cell), Sox17 (32-64 cell), Gata4 (> 58 cell) and Sox7 (>64 cell) (Plusa et al. 2008, Artus et al. 2011).

How is the heterogenic distribution of epi-and hypoblast progenitors established? After some initially opposing conclusions (Morris et al. 2010, Yamanaka et al. 2010), the following model has emerged (Morris et al. 2013, Krupa et al. 2014). The first wave of cells to be internalised have a tendency to contribute to epiblast, particularly when the total number of such cells are low. Conversely the second wave of cells tend to contribute more hypoblast cells. These tendencies appear to be related to Fgf signalling where first wave internalised cells show higher Fgf 4 expression than second wave inner cells, while the reverse is true for the Fgf receptor, Fgfr 2 . This reciprocity had been previously seen between inner and outer cells at the 32-cell stage (Guo et al. 2010). It is thus possible that the longer exposure of second wave inner cells to an outside environment had predisposed them to increased Fgfr 2 and decreased Fgf4 expression. The bias in Fgf signalling and/ or response would be expected to modulate the initially co-expressed Nanog and Gata6 genes. In line with this, inhibition of Fgf signalling switches all ICM cells to Nanog +, Gata6- epiblast, while Fgf4 exposure results in Gata6+, Nanog- hypoblast progenitors (Yamanaka et al. 2010). Fgf signals via the Map kinase (MAPK) cascade. The onset of Gata6 expression was shown to be only initially directly dependent on MAPK signalling (Frankenberg et al. 2011), though such signalling may not be exclusively dependent on Fgf4 (Kang et al. 2013). In cells less responsive to MAPK signalling, Nanog cell-autonomously counteracts Gata6 expression via direct binding and repression in the proximal promoter (Singh et al. 2007) and/or by negatively regulating the Gata6-stabilising Bmi protein (Lavial et al. 2012). Conversely, in cells expressing higher amounts of Fgfr 2, Fgf leads to downregulation of Nanog, thus lifting Gata6 repression (Frankenberg et al. 2011). From the 64-cell stage, when reciprocal expression of Nanog and Gata6 is established, Fgf4 expression becomes dependent on and restricted to Nanog expressing cells. This signal is required to maintain Sox17 and Gata4 expression in the surrounding Gata6 positive cells so as to allow these to acquire full hypoblast character (Messerschmidt \& Kemler 2010, Frankenberg et al. 2011). 
Interestingly, cattle epiblast/hypoblast segregation shows some substantial differences. Gata4, which is expressed subsequent to Gata6 and restricted to prospective hypoblast cells in mice, instead exhibits widespread expression in cattle expanded blastocysts (Kuijk et al. 2012). Secondly, although Nanog and Gata6 are expressed in a mutually exclusive salt and pepper pattern within the ICM of cattle expanded blastocyst, similar to what is seen in 64-cell midblastocyst mouse embryos, Fgf receptor inactivation via small molecule inhibitors had no effect on lineage segregation. Yet inhibiting MAPK signalling did increase the number of Nanog+ cells and reduced Gata6 + cells albeit not quite as efficiently as in the mouse system (Kuijk et al. 2012). An increase in ICM-specific Nanog mRNA upon MAPK inhibition was independently verified (Harris et al. 2013). Stimulation of MAPK signalling via FGF/heparin treatment elicited the opposite result, again in concurrence with mouse work (Kuijk et al. 2012). This strongly suggests that in cattle another signalling molecule (such as Igf, Egf or Pdgf) working through the MAPK signalling cascade may work in parallel or instead of FGF to specify hypoblast formation.

Notably, in human embryos the difference in hypoblast formation is even more pronounced in that MAPK inhibition had no effect on the establishment of reciprocal Nanog and Gata4/6 expression (Kuijk et al. 2012, Roode et al. 2012). However in both studies the effect of exogenous Fgf treatment was not tested in human embryos, leaving open the possibility that MEK signalling is involved but works in parallel to another signalling mechanism. Some care has to be taken in the interpretation of small molecule inhibitor treatments, as in mouse Fgfr inhibitors produces a phenotype that resembles but is not identical to that caused by lack of endogenous Fgf4 (Kang et al. 2013).

\section{Conclusion}

While the study of lineage segregation in mice is leading to an increasingly clear understanding of the basic cell mechanical and molecular events driving these processes, it is similarly becoming increasingly apparent from recent work in cattle that these events differ substantially among different mammals. Therefore if the problem of high embryo mortality in cattle is to be understood, let alone ameliorated, it is necessary to specifically learn more about this system by direct experimentation in cattle as opposed to inferences from the mouse model system which may or may not be correct.

\section{Acknowledgements}

I acknowledge financial support through MSI grant CONT-20621-LNNR-AGR and RSNZ Marsden Grant 07-AGR-004, and thank my former team members at AgResearch, Debbie Berg, Martyn Donnison, Craig Smith, Ric Broadhurst, David Pearton and Jessica van Leeuwen for their scientific support and stimulating discussions.

\section{References}

Alarcon VB 2010 Cell polarity regulator PARD6B is essential for trophectoderm formation in the preimplantation mouse embryo. Biol Reprod 83 347-358.

Artus J, Piliszek A \& Hadjantonakis AK 2011 The primitive endoderm lineage of the mouse blastocyst: sequential transcription factor activation and regulation of differentiation by Sox17. Dev Biol 350 393-404.

Ayalon N 1978 A review of embryonic mortality in cattle. Journal of Reproduction \& Fertility 54 483-493.

Barcroft LC, Hay-Schmidt A, Caveney A, Gilfoyle E, Overstrom EW, Hyttel P \& Watson AJ 1998 Trophectoderm differentiation in the bovine embryo: 
characterization of a polarized epithelium. J Reprod Fertil 114 327-339.

Berg DK, Smith CS, Pearton DJ, Wells DN, Broadhurst R, Donnison M \& Pfeffer PL 2011 Trophectoderm lineage determination in cattle. Dev Cell 20 244-255.

Berg DK, van Leeuwen J, Beaumont S, Berg M \& Pfeffer PL 2010 Embryo loss in cattle between Days 7 and 16 of pregnancy. Theriogenology 73 250-260.

Betteridge KJ \& Flechon JE 1988 The anatomy and physiology of pre-attachment bovine embryos. Theriogenology 29 155-187.

Boyd H, Bacsich P, Young A \& McCracken JA 1969 Fertilization and embryonic survival in dairy cattle. British Veterinary Journal 125 87-97.

Boyer LA, Lee TI, Cole MF, Johnstone SE, Levine SS, Zucker JP, Guenther MG, Kumar RM, Murray HL, Jenner RG, Gifford DK, Melton DA, Jaenisch R \& Young RA 2005 Core transcriptional regulatory circuitry in human embryonic stem cells. Cell 122 947-956.

Burke CR, Tiddy R \& Beukes PC 2008 Case studies exploring the potential impact of farm system changes on herd reproductive performance, production and profitability. Proceedings of the Dairy Cattle Veterinarians Conference 268 25-33.

Cauffman G, Van de Velde H, Liebaers I \& Van Steirteghem A 2005 Oct-4 mRNA and protein expression during human preimplantation development. Mol Hum Reprod 11 173-181.

Chazaud C, Yamanaka Y, Pawson T \& Rossant J 2006 Early lineage segregation between epiblast and primitive endoderm in mouse blastocysts through the Grb2-MAPK pathway. Dev Cell 10 615-624.

Chen L, Yabuuchi A, Eminli S, Takeuchi A, Lu CW, Hochedlinger K \& Daley GQ 2009 Cross-regulation of the Nanog and Cdx2 promoters. Cell Res 19 1052-1061.

Choi I, Carey TS, Wilson CA \& Knott JG 2013 Evidence that transcription factor AP-2gamma is not required for Oct4 repression in mouse blastocysts. PLoS One 8 e65771.

Cockburn K, Biechele S, Garner J \& Rossant J 2013 The Hippo pathway member $\mathrm{Nf} 2$ is required for inner cell mass specification. Curr Biol 23 1195-1201.

Copp AJ 1979 Interaction between inner cell mass and trophectoderm of the mouse blastocyst. II. The fate of the polar trophectoderm. J Embryol Exp Morphol 51 109-120.

Dard N, Louvet-Vallee S \& Maro B 2009 Orientation of mitotic spindles during the 8- to 16-cell stage transition in mouse embryos. PLoS One 4 e8171.

De Paepe C, Cauffman G, Verloes A, Sterckx J, Devroey P, Tournaye H, Liebaers I \& Van de Velde H 2013 Human trophectoderm cells are not yet committed. Hum Reprod 28 740-749.

Dietrich JE \& Hiiragi T 2007 Stochastic patterning in the mouse pre-implantation embryo. Development 134 4219-4231.

Diskin MG \& Morris DG 2008 Embryonic and early foetal losses in cattle and other ruminants. Reprod Domest Anim 43 Suppl 2 260-267.

Diskin MG, Parr MH \& Morris DG 2011 Embryo death in cattle: an update. Reprod Fertil Dev 24 244-251.

Diskin MG \& Sreenan JM 1980 Fertilization and embryonic mortality rates in beef heifers after artificial insemination. J Reprod Fertil 59 463-468.

Dunne LD, Diskin MG \& Sreenan JM 2000 Embryo and foetal loss in beef heifers between day 14 of gestation and full term. Anim Reprod Sci 58 39-44.

Dyce J, George M, Goodall H \& Fleming TP 1987 Do trophectoderm and inner cell mass cells in the mouse blastocyst maintain discrete lineages? Development 100 685-698.

Frankenberg S, Gerbe F, Bessonnard S, Belville C, Pouchin P, Bardot O \& Chazaud C 2011 Primitive endoderm differentiates via a three-step mechanism involving Nanog and RTK signaling. Dev Cell 21 1005-1013.

Grabarek JB, Zyzynska K, Saiz N, Piliszek A, Frankenberg S, Nichols J, Hadjantonakis AK \& Plusa B 2012 Differential plasticity of epiblast and primitive endoderm precursors within the ICM of the early mouse embryo. Development 139 129-139.

Guillomot M 1995 Cellular interactions during implantation in domestic ruminants. J Reprod Fertil Suppl 49 39-51.

Guo G, Huss M, Tong GQ, Wang C, Li Sun L, Clarke ND \& Robson P 2010 Resolution of cell fate decisions revealed by single-cell gene expression analysis from zygote to blastocyst. Dev Cell 18 675-685.

Harris D, Huang B \& Oback B 2013 Inhibition of MAP2K and GSK3 signaling promotes bovine blastocyst development and epiblast-associated expression of pluripotency factors. Biol Reprod 8874.

Hirate Y, Hirahara S, Inoue K, Suzuki A, Alarcon VB, Akimoto K, Hirai T, Hara T, Adachi M, Chida K, Ohno S, Marikawa Y, Nakao K, Shimono A \& Sasaki H 2013 Polarity-dependent distribution of angiomotin localizes Hippo signaling in preimplantation embryos. Curr Biol 23 1181-1194.

Johnson MH \& Ziomek CA 1981 The foundation of two distinct cell lineages within the mouse morula. Cell $\mathbf{2 4}$ 71-80.

Johnson WH, Loskutoff NM, Plante Y \& Betteridge KJ 1995 Production of four identical calves by the separation of blastomeres from an in vitro derived four-cell embryo. Vet Rec 137 15-16.

Kang M, Piliszek A, Artus J \& Hadjantonakis AK 2013 FGF4 is required for lineage restriction and salt-andpepper distribution of primitive endoderm factors but not their initial expression in the mouse. Development 140 267-279.

Khan DR, Dube D, Gall L, Peynot N, Ruffini S, Laffont L, Le Bourhis D, Degrelle S, Jouneau A \& Duranthon V 2012 Expression of pluripotency master regulators during two key developmental transitions: EGA and early lineage specification in the bovine embryo. PLoS One 7 e34110.

Kobolak J, Kiss K, Polgar Z, Mamo S, Rogel-Gaillard C, Tancos Z, Bock I, Baji AG, Tar K, Pirity MK \& Dinnyes A 2009 Promoter analysis of the rabbit POU5F1 gene and its expression in preimplantation stage embryos. BMC Mol Biol 1088.

Koyama H, Suzuki H, Yang X, Jiang S \& Foote RH 1994 Analysis of polarity of bovine and rabbit embryos by scanning electron microscopy. Biol Reprod 50 163-170.

Krupa M, Mazur E, Szczepanska K, Filimonow K, 
Maleszewski M \& Suwinska A 2014 Allocation of inner cells to epiblast vs primitive endoderm in the mouse embryo is biased but not determined by the round of asymmetric divisions (8-> 16- and 16-> 32-cells). Dev Biol 385 136-148.

Kuijk EW, Du Puy L, Van Tol HT, Oei CH, Haagsman HP, Colenbrander B \& Roelen BA 2008 Differences in early lineage segregation between mammals. Dev Dyn 237 918-927.

Kuijk EW, van Tol LT, Van de Velde $H$, Wubbolts $R$, Welling M, Geijsen N \& Roelen BA 2012 The roles of FGF and MAP kinase signaling in the segregation of the epiblast and hypoblast cell lineages in bovine and human embryos. Development 139 871-882.

Kurotaki Y, Hatta K, Nakao K, Nabeshima Y \& Fujimori T 2007 Blastocyst axis is specified independently of early cell lineage but aligns with the ZP shape. Science $\mathbf{3 1 6}$ 719-723.

Lavial F, Bessonnard S, Ohnishi Y, Tsumura A, Chandrashekran A, Fenwick MA, Tomaz RA, Hosokawa H, Nakayama T, Chambers I, Hiiragi T, Chazaud C \& Azuara V 2012 Bmi1 facilitates primitive endoderm formation by stabilizing Gata6 during early mouse development. Genes Dev 26 1445-1458.

Lorthongpanich C, Doris TP, Limviphuvadh V, Knowles BB \& Solter D 2012 Developmental fate and lineage commitment of singled mouse blastomeres. Development 139 3722-3731.

Maurer RR \& Chenault JR 1983 Fertilization failure and embryonic mortality in parous and nonparous beef cattle. J Anim Sci 56 1186-1189.

McDougall S, Rhodes FM \& Verkerk G 2005 Pregnancy loss in dairy cattle in the Waikato region of New Zealand. $N$ Z Vet J 53 279-287.

Messerschmidt DM \& Kemler R 2010 Nanog is required for primitive endoderm formation through a non-cell autonomous mechanism. Dev Biol 344 129-137.

Morris SA, Graham SJ, Jedrusik A \& Zernicka-Goetz M 2013 The differential response to Fgf signalling in cells internalized at different times influences lineage segregation in preimplantation mouse embryos. Open Biol 3130104

Morris SA, Guo Y \& Zernicka-Goetz M 2012 Developmental plasticity is bound by pluripotency and the Fgf and Wnt signaling pathways. Cell Rep 2 756-765.

Morris SA, Teo RT, Li H, Robson P, Glover DM \& ZernickaGoetz M 2010 Origin and formation of the first two distinct cell types of the inner cell mass in the mouse embryo. Proc Natl Acad Sci U S A 107 6364-6369.

Nagatomo H, Kagawa S, Kishi Y, Takuma T, Sada A, Yamanaka K, Abe Y, Wada Y, Takahashi M, Kono T \& Kawahara M 2013 Transcriptional wiring for establishing cell lineage specification at the blastocyst stage in cattle. Biol Reprod $\mathbf{8 8} 158$.

Nishioka N, Inoue K, Adachi K, Kiyonari H, Ota M, Ralston A, Yabuta N, Hirahara S, Stephenson RO, Ogonuki N, Makita R, Kurihara H, Morin-Kensicki EM, Nojima H, Rossant J, Nakao K, Niwa H \& Sasaki H 2009 The Hippo signaling pathway components Lats and Yap pattern Tead4 activity to distinguish mouse trophectoderm from inner cell mass. Dev Cell 16 398-410.
Nishioka N, Yamamoto S, Kiyonari H, Sato H, Sawada A, Ota M, Nakao K \& Sasaki H 2008 Tead4 is required for specification of trophectoderm in pre-implantation mouse embryos. Mech Dev 125 270-283.

Nishiyama A, Xin L, Sharov AA, Thomas M, Mowrer G, Meyers E, Piao Y, Mehta S, Yee S, Nakatake Y, Stagg C, Sharova L, Correa-Cerro LS, Bassey U, Hoang H, Kim E, Tapnio R, Qian Y, Dudekula D, Zalzman M, Li M, Falco G, Yang HT, Lee SL, Monti M, Stanghellini I, Islam MN, Nagaraja R, Goldberg I, Wang W, Longo DL, Schlessinger D \& Ko MS 2009 Uncovering early response of gene regulatory networks in ESCs by systematic induction of transcription factors. Cell Stem Cell 5 420-433.

Niwa H, Toyooka Y, Shimosato D, Strumpf D, Takahashi K, Yagi R \& Rossant J 2005 Interaction between Oct3/4 and $\mathrm{Cd} \times 2$ determines trophectoderm differentiation. Cell 123 917-929.

Ozawa M, Sakatani M, Yao J, Shanker S, Yu F, Yamashita R, Wakabayashi S, Nakai K, Dobbs KB, Sudano MJ, Farmerie WG \& Hansen PJ 2012 Global gene expression of the inner cell mass and trophectoderm of the bovine blastocyst. BMC Dev Biol 1233.

Pedersen RA, Wu K \& Balakier H 1986 Origin of the inner cell mass in mouse embryos: cell lineage analysis by microinjection. Dev Biol 117 581-595.

Peyrieras N, Hyafil F, Louvard D, Ploegh HL \& Jacob F 1983 Uvomorulin: a nonintegral membrane protein of early mouse embryo. Proc Natl Acad Sci U S A 80 6274-6277.

Pfeffer PL \& Pearton DJ 2012 Trophoblast development. Reproduction 143 231-246.

Picard L, Chartrain I, King WA \& Betteridge KJ 1990 Production of chimaeric bovine embryos and calves by aggregation of inner cell masses with morulae. Mol Reprod Dev 27 295-304.

Plachta N, Bollenbach T, Pease S, Fraser SE \& Pantazis P 2011 Oct4 kinetics predict cell lineage patterning in the early mammalian embryo. Nat Cell Biol 13 117-123.

Plusa B, Frankenberg S, Chalmers A, Hadjantonakis AK, Moore CA, Papalopulu N, Papaioannou VE, Glover DM \& Zernicka-Goetz M 2005 Downregulation of Par3 and aPKC function directs cells towards the ICM in the preimplantation mouse embryo. J Cell Sci 118 505-515.

Plusa B, Piliszek A, Frankenberg S, Artus J \& Hadjantonakis AK 2008 Distinct sequential cell behaviours direct primitive endoderm formation in the mouse blastocyst. Development 135 3081-3091.

Ralston A, Cox BJ, Nishioka N, Sasaki H, Chea E, Rugg-Gunn P, Guo G, Robson P, Draper JS \& Rossant J 2010 Gata3 regulates trophoblast development downstream of Tead4 and in parallel to Cdx2. Development 137 395-403.

Ralston A \& Rossant J 2008 Cdx2 acts downstream of cell polarization to cell-autonomously promote trophectoderm fate in the early mouse embryo. Dev Biol 313 614-629.

Roche JF, Boland MP \& McGeady TA 1981 Reproductive wastage following artificial insemination of heifers. Vet Rec 109 401-404.

Roode M, Blair K, Snell P, Elder K, Marchant S, Smith A \& Nichols J 2012 Human hypoblast formation is not dependent on FGF signalling. Dev Biol 361 358-363. 
Rossant J \& Lis WT 1979 Potential of isolated mouse inner cell masses to form trophectoderm derivatives in vivo. Dev Biol 70 255-261.

Rossant J \& Vijh KM 1980 Ability of outside cells from preimplantation mouse embryos to form inner cell mass derivatives. Dev Biol 76 475-482.

Sartori R, Bastos MR \& Wiltbank MC 2010 Factors affecting fertilisation and early embryo quality in single- and superovulated dairy cattle. Reprod Fertil Dev 22 151-158.

Singh AM, Hamazaki T, Hankowski KE \& Terada N 2007 A heterogeneous expression pattern for Nanog in embryonic stem cells. Stem Cells 25 2534-2542.

Skamagki M, Wicher KB, Jedrusik A, Ganguly S \& ZernickaGoetz M 2013 Asymmetric localization of Cdx2 mRNA during the first cell-fate decision in early mouse development. Cell Rep 3 442-457.

Sritanaudomchai H, Sparman M, Tachibana M, Clepper L, Woodward J, Gokhale S, Wolf D, Hennebold J, Hurlbut W, Grompe M \& Mitalipov S 2009 CDX2 in the formation of the trophectoderm lineage in primate embryos. Dev Biol 335 179-187.

Stephenson RO, Yamanaka Y \& Rossant J 2010 Disorganized epithelial polarity and excess trophectoderm cell fate in preimplantation embryos lacking E-cadherin. Development 137 3383-3391.

Strumpf D, Mao CA, Yamanaka Y, Ralston A, Chawengsaksophak K, Beck F \& Rossant J 2005 $\mathrm{Cd} 2 \mathrm{2}$ is required for correct cell fate specification and differentiation of trophectoderm in the mouse blastocyst. Development 132 2093-2102.

Suwinska A, Czolowska R, Ozdzenski W \& Tarkowski AK 2008 Blastomeres of the mouse embryo lose totipotency after the fifth cleavage division: expression of $\mathrm{Cd} \times 2$ and Oct4 and developmental potential of inner and outer blastomeres of 16- and 32-cell embryos. Dev Biol 322 133-144.

Szczepanska K, Stanczuk L \& Maleszewski M 2011 Isolated mouse inner cell mass is unable to reconstruct trophectoderm. Differentiation 82 1-8.

Tang F, Barbacioru C, Nordman E, Bao S, Lee C, Wang X, Tuch BB, Heard E, Lao K \& Surani MA 2011 Deterministic and stochastic allele specific gene expression in single mouse blastomeres. PLoS One 6 e21208.

Tarkowski AK, Suwinska A, Czolowska R \& Ozdzenski W 2010 Individual blastomeres of 16- and 32-cell mouse embryos are able to develop into foetuses and mice. Dev Biol 348 190-198.

Tarkowski AK \& Wroblewska J 1967 Development of blastomeres of mouse eggs isolated at the 4- and 8-cell stage. J Embryol Exp Morphol 18 155-180. van Eijk MJ, van Rooijen MA, Modina S, Scesi L, Folkers G, van Tol HT, Bevers MM, Fisher SR, Lewin HA, Rakacolli D, Galli C, de Vaureix C, Trounson AO, Mummery CL \& Gandolfi F 1999 Molecular cloning, genetic mapping, and developmental expression of bovine POU5F1. Biol Reprod 60 1093-1103.

Van Soom A, Boerjan ML, Bols PE, Vanroose G, Lein A, Coryn M \& de Kruif A 1997 Timing of compaction and inner cell allocation in bovine embryos produced in vivo after superovulation. Biol Reprod 57 1041-1049.

Walsh SW, Williams EJ \& Evans AC 2011 A review of the causes of poor fertility in high milk producing dairy cows. Anim Reprod Sci 123 127-138.

Wang K, Sengupta S, Magnani L, Wilson CA, Henry RW \& Knott JG 2010 Brg1 is required for Cdx2-mediated repression of Oct4 expression in mouse blastocysts. PLoS One 5 e10622.

Wennekamp S, Mesecke S, Nedelec F \& Hiiragi T 2013 A self-organization framework for symmetry breaking in the mammalian embryo. Nat Rev Mol Cell Biol 14 452-459.

Wiebold JL 1988 Embryonic mortality and the uterine environment in first-service lactating dairy cows. J Reprod Fertil 84 393-399.

Willadsen SM 1981 The development capacity of blastomeres from 4-and 8-cell sheep embryos. J Embryol Exp Morphol 65 165-172.

Winters LM, Green WW \& Comstock RE 1942 Prenatal Development of the Bovine. Minnesota Technical Bulletin 151 3-50.

Xie D, Chen CC, Ptaszek LM, Xiao S, Cao X, Fang F, Ng HH, Lewin HA, Cowan C \& Zhong S 2010 Rewirable gene regulatory networks in the preimplantation embryonic development of three mammalian species. Genome Res 20 804-815.

Xue Z, Huang K, Cai C, Cai L, Jiang CY, Feng Y, Liu Z, Zeng Q, Cheng L, Sun YE, Liu JY, Horvath S \& Fan G 2013 Genetic programs in human and mouse early embryos revealed by single-cell RNA sequencing. Nature $\mathbf{5 0 0}$ 593-597.

Yagi R, Kohn MJ, Karavanova I, Kaneko KJ, Vullhorst D, DePamphilis ML \& Buonanno A 2007 Transcription factor TEAD4 specifies the trophectoderm lineage at the beginning of mammalian development. Development 134 3827-3836.

Yamanaka Y, Lanner F \& Rossant J 2010 FGF signaldependent segregation of primitive endoderm and epiblast in the mouse blastocyst. Development 137 715-724. 
